\title{
Factor Affecting the Coverage of Ideal K1 Antenatal Services in the Work Area of the Batu Putih Public Health Center, Sub-District Batu Putih, District Timor Tengah Selatan
}

Yudistira Kikhau ${ }^{*}$, Christina O. Lada² , Paula Tibuludji², Andreas Umbu Roga², Pius Weraman²
'Public Health Sciences Students, Post-Graduate Program, Nusa Cendana University, Kupang-85001, East Nusa Tenggara - Indonesia
2Public Health Sciences Lecturer, Post-Graduate Program, Nusa Cendana University, Kupang-85001, East Nusa Tenggara - Indonesia

Article History

Received: 18.01.2021

Accepted: 31.01 .2021

Published: 24.03 .2021

Journal homepage: https://www.easpublisher.com

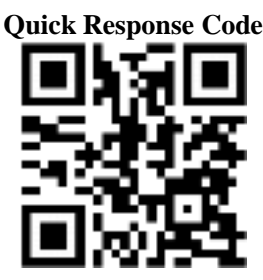
women who receive antenatal care for the first time, namely in the first trimester by health workers who have competency according to standards, in a work area at a certain time. It is expected that pregnant women who receive prenatal care as early as possible according to standards can avoid risk occurrence of complications during pregnancy, childbirth and post-partum. The coverage of K1 Ideal services is influenced by predisposing factors, namely age, parity, education, knowledge and attitudes, and enabling factors, namely accessibility and reinforcing factors, namely support from husbands, support from in-laws and socio-culture. The purpose of this study was to analyze the factors that influence the coverage of antenatal care for K1 Ideal in the Batu Putih Public Health Center area, Batu Putih Sub-District, South Central Timor District. This research is a quantitative analytic study with a cross sectional study design with a total sample of 101 respondents. The statistical analysis used was univariate, vicariate and multivariate analysis. Result: The results showed that the factor that significantly affected the antenatal coverage of K1 Ideal was the level of education $(p=0.000)$ with a value of Prevalence Ratio $(\mathrm{RP})=23.397$. While factors do not have a significant effect on antenatal coverageK1 Ideal is. Ages $(\mathrm{p}=0.275)$, knowledge $(\mathrm{p}=0.392)$, parity ( $\mathrm{p}$ $=0.078)$ attitude $(0.997)$, accessibility $(\mathrm{p}=0316)$, husband's support $(\mathrm{p}=0528)$, support from in-laws $(\mathrm{p}=0.959)$ and socio-culture $(\mathrm{p}=0.799)$ and the dominant factor which has a significant effect on antenatal coverage. K1 Ideal is the level of education $(\mathrm{p}$ value $=0.000 ; \mathrm{OR}=7.732$ ). In order to increase the coverage of $\mathrm{K} 1$ Ideal antenatal services at Public Health Center Batu Putih, it is hoped that health workers, especially midwives, can increase efforts to promote antenatal care through counseling with effective methods and media according to the level of education of pregnant women.

Keywords: Ideal K1 antenatal care coverage, age, education, knowledge, attitudes, husband's support, in-laws support, socio-culture.

Copyright (C) 2021 The Author(s): This is an open-access article distributed under the terms of the Creative Commons Attribution 4.0 International License (CC BY-NC 4.0) which permits unrestricted use, distribution, and reproduction in any medium for non-commercial use provided the original author and source are credited.

\section{Preliminary}

Antenatal care is a health service provided by professional health professionals (obstetricians and midwives, general practitioners and midwives) to pregnant women during their pregnancy, which follows existing antenatal care guidelines and prioritizes promotional and preventive activities [1]. Antenatal care is provided to pregnant women by health workers in health care facilities. This process is carried out during the range of maternal gestational age grouped according to gestational age into the first trimester, second trimester and third trimester. Maternal health services must meet the minimum frequency in each semester, namely once in the first trimester (0-12 weeks of gestation), once in the second trimester (12-24 weeks of gestation), and twice in the third trimester (gestational age 24 weeks until delivery [1].

The World Health Organization [2] estimates that about $15 \%$ of all pregnant women will develop problems or complications at any time and can threaten their lives. Prenatal check-ups as early as possible according to antenatal service standards, namely ideal $\mathrm{K} 1$ visits according to standards (gestational age 0-12 weeks) is important to ensure that 
natural processes run normally during pregnancy, so as to reduce Maternal Mortality Rate (MMR) [3]. Antenatal care as early as possible in the first trimester of pregnancy (0-12 weeks) can detect fetal growth disorders, hypertension in pregnancy, nutritional status of pregnant women at risk of Chronic Energy Deficiency (KEK) so as not to give birth to Low Birth Weight (LBW) babies, abnormalities location of the fetus, immunization status, preventing iron nutrition anemia and laboratory examinations (blood type, sugar levels, malaria) [4].

The National Basic Health Research 2018 report shows that the coverage of $\mathrm{K} 1$ antenatal care in East Nusa Tenggara (NTT) is $94.0 \%, 17.9 \%$ lower than that of the National K1 coverage of $96.1 \%$. Meanwhile, the ideal K1 antenatal care coverage in NTT Province is $73.9 \%, 12.1 \%$ lower than the national ideal $\mathrm{K} 1$, which is $86 \%$. For the coverage of antenatal care for $\mathrm{k} 4$ provi nsi in NTT, there is a difference of $9.8 \%$ lower, namely $64.3 \%$ when compared to the National K4 with $74.1 \%$. Based on the explanation of the data above, in NTT Province there is a difference or gap between ideal $\mathrm{K} 1$ and $\mathrm{K} 4$ antenatal care coverage of $9.6 \%$ of mothers who received $\mathrm{K} 1$ Ideal did not continue ANC according to the minimum standard (K4) [5].

Referring to data from the Health Office of Timor Tengah Selatan District for the last three years, namely 2017 to 2019, the ideal K1 antenatal service coverage in TTS District in the work area of Public Health Center Batu Putih has fluctuated and has not reached the Strategic Plan and SPM targets, namely 148 visits from the total 348 visits for $\mathrm{K} 1$ antenatal services $(42.5 \%)$ in 2017,94 out of a total of 254 visits for K1 antenatal services (37\%) in 2018 and again increased with the number of visits to 135 from a total of 612 visits for K1 antenatal services (22.05\%) in 2019 (TTS Sub-District Health Office, 2017-2019).

The K1 Ideal antenatal service visit can be influenced by several factors including age, educational parity, knowledge, attitudes, husband's support, and socio-culture. The results of previous research by Hidayatun, MS [6] showed that the level of maternal education influenced the behavior of ANC visits, because mothers with a high level of education tended to carry out antenatal examinations as early as possible and tended to regularly make antenatal visits compared to mothers with lower educational levels.

Timor Tengah Selatan District has a very large area and has 36 Public Health Center. Low Coverage of Antenatal K1 Ideal influenced by various factors that coverage service Antenatal be less than optimal. This study focused on factors predisposing (age, parity, education, knowledge and attitude), reinforcing factors (accessibility/geography) and factors support (husband's support, the support of laws and social -cultural) that affect coverage Antenatal care K1 Ideal in PHC Batu Putih sub-Sub-District Batu Putih, TTS District.

Objective research is to analyze the factors that influence on antenatal care coverage $\mathrm{K} 1$ ideal in the region of Batu Putih Public health centers, sub-SubDistrict Batu Putih South Central Timor. The scope research is focused on the factors pre- disposition (age, parity, education, $\mathrm{p}$ What Knowledge and attitude), reinforcing factors (accessibility/geography) and factors support (husband's support, the support of laws and social -cultural) that affect the scope Ideal K1 antenatal care at the Batu Putih Public Health Center, Batu Putih sub-Sub-District, TTS District.

\section{Research Methods}

This research is quantitative analytic study wit h cross-sectional design using an observational approach or one-time data collection (point time approach) in other words; the independent variable and the dependent variable are seen simultaneously at the same time. The populations in this study were all pregnant women who made the ideal first antenatal visit (K1) in 2019 in the Batu PutihPublic health center area, Batu Putih Sub-District, TTS District.

The sample in this study was taken by simple random sampling method with a total sample of 101 people. The criteria that must be met as a consideration for sample selection in this study are inclusion and exclusion criteria. The data collected are primary and secondary data. Primary data in this study are age, education, parity, knowledge, attitudes, accessibility, husband's support, in-laws and socio-cultural support. Secondary data were obtained from authorized government agencies, namely the health profile of the TTS Sub-District, the Profile of the Batu Putih Public Health Center and data on the number of pregnant women who visited the ideal K1 antenatal examination. Data collection in this study was carried out by conducting interviews using a questionnaire.

Researchers conducted univariate analysis to determine the frequency distribution of each -massing variables, vicariate analysis to examine the relationship between the independent variables withdependent variable use be a statistical test Chi-Square (2) and multivariate analysis to examine the effect of each independent variable together to the dependent variable using multiple logistic regression statistical tests.

\section{RESULTS AND DisCUSSION}

The research was conducted in the work area of Public Health Center Batu Putih, Timor Tengah Selatan District, with the research subjects of pregnant women who visited the ideal $\mathrm{K} 1$ antenatal pregnancy examination in 2019, totaling 101 people. Geographically, Public Health Center Batu Putih is located in Batu Putih Sub-District, Timor Tengah Selatan District (TTS). Batu Putih Public Health Center 
is located in the village of Oebobo, $\pm 33 \mathrm{~km}$ from the Sub-District capital with a distance of about 1 hour using motorbikes and public transportation. Batu Putih Sub-District has an area of $102.32 \mathrm{Km}^{2}$ which is divided into 7 villages consisting of 23 hamlets, 54 RW and $125 \mathrm{RT}$. The largest village area is Hane Village $\left(19.77 \mathrm{Km}^{2}\right)$ while the smallest village is Tuakole Village $\left(10.55 \mathrm{Km}^{2}\right)$.

Total population in Public Health Center Batu Putih is 12892 inhabitants with details of the number of males as many as 6485 lives and as many as 6,407 female population to the total number of head of K eluarga 3172 [7]. From an economic point of view, the majority of the population in the working area of the Batu Putih Public health center work as farmers which includes rice, corn, banana, peanut, coconut, chili, vegetable and other farmers. Apart from being a farmer there are also those who rise, trade, carpentry, mason and other jobs such as sand mining [8]. Ethnic diversity is found in Batu Putih Sub-District, but the Timorese still dominate in number, there are also the Rote, Sabu and a small number of various tribes who come from inside and outside the East Nusa Tenggara region. With this diversity of tribes, there are also customs that enter the Batu Putih Sub-District area [9].

Characteristics of respondents, the ideal age of mothers who visited the $\mathrm{K} 1$ antenatal examination in the working area of Public Health Center Batu Putih, TTS District, was mostly in the age category without risk of 20-35 years. The education of mothers who visited the ideal $\mathrm{K} 1$ antenatal examination in the working area of Public Health Center Batu Putih, TTS District, was mostly in the low education category (<SMA ). Most of the mothers who visited the ideal $\mathrm{K} 1$ antenatal examination in the working area of the Puskesmas Batu Putih TTS District were in the high parity category (> 4 times) and most of the mothers did not work (housewives).

Table-1: Distribution of frequency characteristics of mothers who visit ideal K1 antenatal services in the working area of Public Health Center Batu Putih, TTS District

\begin{tabular}{|l|c|c|}
\hline Respondent Characteristics & Frequency & Percentage (\%) \\
\hline Age & & \\
\hline At risk $(<20 \&>35$ years) & 23 & 22.8 \\
\hline No Risk (20 - 35 Years) & 78 & 77.2 \\
\hline Total & 101 & 100 \\
\hline Education & & \\
\hline High (> SMA) & 40 & 40.6 \\
\hline Low (<SMA) & 61 & 60.4 \\
\hline Total & 101 & 100 \\
\hline Parity & & \\
\hline High (> SMA) & 30 & 29.7 \\
\hline Low (<SMA) & 71 & 70.3 \\
\hline Total & 101 & 100 \\
\hline Profession & & \\
\hline Not Working (Housewife) & 99 & 98.2 \\
\hline Work (ASN, private employees, self-employed, farmers, laborers) & 2 & 1.98 \\
\hline Total & 101 & 100 \\
\hline Knowledge & & \\
\hline Good ( $\geq 50 \%)$ & 30 & 29.7 \\
\hline Less Good $(\leq 50 \%)$ & 71 & 70.3 \\
\hline Total & 101 & 100 \\
\hline Attitude & & \\
\hline Good $(\geq$ mean $)$ & 58 & 57.4 \\
\hline Less Good $(\leq$ mean $)$ & 43 & 42.6 \\
\hline Total & 101 & 100 \\
\hline
\end{tabular}

\begin{tabular}{|l|c|c|}
\hline Accessibility & & \\
\hline Easy $(<30$ minutes, $<3 \mathrm{~km}$, there is public / private transport) & 68 & 67.3 \\
\hline Difficult $(\geq 30$ minutes, $\geq 3 \mathrm{~km}$, no transportation) & 33 & 32.7 \\
\hline Total & 101 & 100 \\
\hline Husband's Support & & \\
\hline Support $(\geq$ mean $)$ & 76 & 75.2 \\
\hline Unsupported $(\leq$ mean $)$ & 25 & 24.8 \\
\hline Total & 101 & 100 \\
\hline In-laws support & & \\
\hline Support $(\geq$ mean $)$ & 47 & 46.5 \\
\hline Unsupported $(\leq$ mean $)$ & 54 & 53.5 \\
\hline Total & 101 & 100 \\
\hline Socio-cultural & & \\
\hline There is influence $(\geq$ mean $)$ & 27 & 26.7 \\
\hline No Effect $(\leq$ mean $)$ & 74 & 73.3 \\
\hline Total & 101 & 100 \\
\hline
\end{tabular}


Age. Statistical test a relationship between age with ideal K1 antenatal care coverage using ChiSquare $\left(^{2}\right)$ obtained $\mathrm{p}=0,275(>0.05), \quad$ it can be concluded no effect of age on coverage visit of antenatal care (ANC) K1 ideal.

The RP value of the age variable is 1.682 , meaning that respondents with no risk age (20-35 years) have the possibility of 1.682 times to visit antenatal care (ANC) compared to respondents with a risk age. Ages affects antenatal care, because the more old enough, the level of maturity and strength of a person will be more mature in thinking, so that a sufficient age will make the mother think mature about her health needs, one of which is to check the pregnancy with health workers from an early age [10]. On the contrary, according to Hermina Humune [11], if a person's age is too young to get pregnant $(<20$ years), the level of awareness of the importance of pregnancy checks is not enough and the age is too old (> 35 years) they already have experience with previous pregnancies so that the awareness antenatal care is also lacking. Age that is not too old or not too young (20-35 years) will make mothers think mature and act wisely in making decisions concerning their own health. Pregnant women aged 20-35 years will think that antenatal care is important for the health of themselves and their fetuses so that mothers check their pregnancies as early as possible since they find out that they are pregnant / late menstruation. Pregnant women who are 35 years old usually have many children. The more children are born, the lower the motivation of the mother to have her pregnancy checked because in addition to the mother being busy taking care of her children, the mother also feels that pregnancy is a normal thing for the mother.

Education. The statistical test of the relationship between education and ideal $\mathrm{K} 1$ antenatal care coverage using Chi-Square $\left(X^{2}\right)$ obtained $\mathrm{p}$ value $=$ $0.000(<0.05)$, it can be concluded that there is an effect of education on the ideal K1 antenatal care coverage. In addition, the value of RP $=23.397$ means that respondents who have a high level of education have 23.397 opportunities to make an ideal K1 antenatal examination visit compared to respondents with low levels. The level of maternal education influences the behavior of antenatal service visits, namely mothers with a high level of education tend to carry out antenatal examinations as early as possible and tend to routinely perform antenatal check-up visits compared to mothers with lower educational levels. The level of education is an important factor to motivate someone to behave well, in this case, to behave in a healthy manner, including early pregnancy checks and routine antenatal care according to standards in health facilities. The higher the level of education of the mother, the more motivated she is to carry out her prenatal care as early as possible and vice versa. The level of education is also a factor that plays a role in the pregnancy process. The higher the level of education of the mother, the better the information can be sought so that quickly understanding her health condition, the mother will know how to prevent complications in the event of pregnancy and vice versa.

Parity, Statistical test the relationship between parity with K1 ideal antenatal care coverage using ChiSquare $\left({ }^{2}\right)$ obtained by value $\mathrm{p}=0,078(>0.05)$, it can be concluded there is no parity against the influence of antenatal care coverage K1 ideal. The RP value of the parity variable is 2.172 , meaning that respondents with no risk parity have the possibility of 2,172 times to visit antenatal care (ANC) compared to respondents with risk parity. The experience of pregnancy affects the motivation to perform antenatal care. It is likely that most of the respondents are mothers who have experienced pregnancy for the first time so they perceive their pregnancy as something new and feel worried about their pregnancy and feel more in need of information regarding their pregnancy. This is in line with Padila [12] which states that mothers who are pregnant for the first time are very new so that they are motivated to check their pregnancies with health workers. On the other hand, a mother who has given birth to more than one person assumes that she is experienced so that she is not motivated to have her pregnancy checked.

Knowledge. Statistical test the relationship between knowledge and antenatal care coverage K1 ideal using Chi-Square $\left(^{2}\right)$ obtained by value $\mathrm{p}=0,392$ (> 0.05), it can be concluded there is no influence of knowledge on antenatal care coverage K1 ideal. The RP value of the knowledge variable is 1.458 , meaning that respondents with good knowledge have the possibility of 1.458 times to visit the ideal K1 antenatal service (ANC) compared to those with less good knowledge. Someone's knowledge about something can be different, there is good and bad. This depends on education, educational information communication methods (IEC) and facilities for obtaining adequate knowledge about antenatal care. Knowledge about maternal pregnancy is obtained from previous pregnancy experiences so that it is often knowledge that is applied during subsequent pregnancies. Moreover, if the previous pregnancy went well even though she did not have an antenatal care visit, this could affect the mother's behavior in making pregnancy visits.

Attitude. Statistical test the relationship between attitudes to the ideal $\mathrm{K} 1$ antenatal care coverage using the Chi-square $\left(X^{2}\right)$ obtained by value $\mathrm{p}$ $=0,997(>0.05)$, then we can conclude that there is no influence attitudes towards ideal K1 antenatal care coverage. RP value attitudinal variables at 0.998 , it means a respondent who has an attitude both have the possibility of 0.998 times do ideal $\mathrm{K} 1$ antenatal visits (ANC) than who has the attitude is not good. Attitude is 
an important factor in visiting visits to improve maternal and child health so that maternal and child deaths can be prevented. With a good attitude, pregnant women can also respond or assess the importance of antenatal care (ANC) so that the attitude of the mother in antenatal examinations can be improved. This is in line with the statement of Newcomb, a social psychologist who states that attitude is a readiness or willingness to act, not an implementation of a particular motive. Attitude is not yet an action (open reaction) or activity but it is a predisposition of behavior (action) based on closed reactions [13].

Accessibility The statistical test of the relationship between accessibility and ideal K1 antenatal care coverage using Chi-Square $\left(X^{2}\right)$ obtained $\mathrm{p}$ value $=0.316(>0.05)$, it can be concluded that there is no effect of accessibility on ideal $\mathrm{K} 1$ antenatal care coverage. The RP value of the accessibility variable is 0.650 , meaning that respondents who have easy accessibility have the possibility of 0.650 visits to the ideal K1 antenatal service (ANC) compared to those who have difficult accessibility. From the geographical conditions, the Batu Putih sub-Sub-District has challenges for mothers, namely distance and difficult access to facilities, but according to environmental factors and walking habits as one of the factors that remains high number of mothers who visit antenatal care despite difficult accessibility. This is in line with Dever [14] which states that easy access is one of one's choices to take advantage of health services, the short distance or short travel time and the ease of transportation will affect a person in determining health services, the easier one's accessibility to health services. The higher a person can take advantage of these services. Accessibility is one of the supporting factors (enablingfactor). What allows motivating individuals or groups in the ease of reaching health facilities includes distance, travel time and ease of transportation.

Husband's Support statistical test of the relationship between husband's support and ideal K1 antenatal care coverage using Chi-Square $\left(X^{2}\right)$ obtained $\mathrm{p}$ value $=0,528(>0.05)$, it can be concluded that there is no effect of support on ideal $\mathrm{K} 1$ antenatal care coverage. The RP value for the attitude variable is 1.338 , meaning that the respondent whose husband is supportive has the possibility of 1.338 times to visit the ideal K1 antenatal service (ANC) compared to the respondent whose husband is not supportive. Support and participation of husbands during pregnancy increases the readiness of pregnant women in facing pregnancy and childbirth and can even trigger the production of breast milk (ASI). The husband's job is to pay attention and maintain a good relationship with his wife, so that the wife will consult any problems she experiences during pregnancy. Examples of husband support during pregnancy include taking the wife for a light walk, accompanying the wife to check her pregnancy, not causing problems in communicating. Most of those who received support from their husbands but did not make ideal K1 antenatal visits and were still reluctant to come for antenatal care because the respondents' lack of awareness and also because their husbands only recommended to do antenatal care, but their husbands did not accompany the mothers.

In-laws support. The statistical test of the relationship between in-laws support and ideal K1antenatal care coverage using Chi-Square $\left(X^{2}\right)$ obtained $\mathrm{p}$ value $=0,959(>0.05)$, it can be concluded that there is no influence of in-laws support on ideal K1 antenatal care coverage. The RP value of the parent-inlaw support variable is 0.980 , meaning that respondents whose parents-in-law support have a possibility of 0.980 times to visit the ideal $\mathrm{K} 1$ antenatal service (ANC) compared to respondents whose in- laws are not supportive. Support from parents-in-law does not affect pregnant women to carry out antenatal care. The awareness of pregnant women in conducting antenatal care is more related to the knowledge of mothers about the benefits and benefits of conducting antenatal care for the health and safety of mothers and babies during pregnancy and delivery. This is in line with Yulifah and Yuswanto [15] who state that prenatal care visits as early as possible according to antenatal service standards, namely ideal $\mathrm{K} 1$ visits according to standards (gestational age 0-12 weeks) is important to ensure that natural processes run normally during pregnancy, so as to reduce the number. Maternal Death (AKI).

Socio-cultural Statistical test the relationship between so the al cultural ideal $\mathrm{K} 1$ antenatal care coverage using the Chi-square $\left(X^{2}\right)$ obtained by value $\mathrm{p}$ $=0,799(>0.05)$, it can be concluded no social influence of culture on antenatal care coverage K1 ideal. The RP value for the attitude variable was 1.122 , meaning that respondents who stated that there was a socio-cultural influence had the possibility of 1,122 visits to ideal $\mathrm{K} 1$ antenatal care (ANC) compared to those who stated there was no socio-cultural influence. Family behavior that does not allow a woman to leave the house to have her pregnancy checked is a culture that inhibits regular visits for pregnant women to check their pregnancies. Socio-cultural changes consist of cultural values, norms, customs, institutions, and customary laws that are commonly practiced in an area. If this custom is not implemented, there will be poisoning which will result in unwritten sanctions by the local community against the perpetrators who are considered deviant. Cultural structure influences the decision of mothers to check their pregnancies with health workers.

Results of statistical test of the influence of age, education, parity, knowledge, attitude, accessibility, husband support, the support of laws and social culture of the coverage of antenatal care K1 ideal using logistic regression multiple shows $\mathrm{v}$ variable 
which have a significant effect simultaneously is educational variables that have values otherp $=0.000$.

\section{CONCLUSION}

Based on the results of the research, the factors that influence the coverage of K1 Ideal antenatal care in the work area of the Batu Putih Public health center, Bat u Putih Sub-District, Timor Tengah Selatan District, the following conclusions can be drawn:

1. Antenatal care visits K1 Ideal pregnant women are influenced by predisposing factors (age, parity, education, knowledge and attitudes), enabling factors (accessibility) and reinforcing factors (husband support, support from in-laws and social culture). This study proves the existence of the influence of predisposing factors, especially education, which has a very strong effect on maternal K1 antenatal visits. The higher the mother's education, the more ideal $\mathrm{K} 1$ antenatal care coverage. Conversely, the lower the mother's education, the lower the ideal K1 antenatal care coverage. Education level is a predisposing factor that motivates a person to behave in a good or healthy manner. Green [16] includes conducting prenatal care as early as possible in a health facility. The higher the level of education of the mother, the more motivated she is to carry out antenatal care as early as possible in a health facility and vice versa.

2. There is no influence of enabling factors, namely accessibility to the coverage of antenatal care $\mathrm{K} 1$ Ideal with a value of $\mathrm{p}=0.316(>0.05)$.

3. There is no influence of reinforcing factors, namely husband's support, in -laws and socio-cultural support on the coverage of antenatal care. K1 Ideal.

4. No effect in a manner simultaneous factors predisposing, reinforcing factors and enabling factors to the antenatal care coverage K1 Ideal in Public Health Center Batu Putih Batu Putih, Central South Timor Sub-District.

\section{REFERENCE}

1. Ministry of Health of the Republic of Indonesia. (2016). Sustainable Development Goals. Jakarta: Ministry of Health RI
2. Azwar, A. (2010). Maintaining the Quality of Health Services. Jakarta: Sinar Harapan

3. Astuti, P. H. (2012). Textbook of Maternity Care for Mother I (Pregnancy). Yogyakarta: Rohima Press.

4. Ministry of National Education. (2003). Law of the Republic of Indonesia No. 20 of 2003 concerning the National Education System

5. MOH, R.I. (2010). Basic Health Research Research and Development Agency of the Indonesian Ministry of Health. Jakarta

6. Hidayatun, M.S. (2014). Factor Analysis of Pregnant Women on Antenatal Care Visits at Siwalankerto Public Public health center, Wonocolo Sub-District, Surabaya City. Journal of Health Promotion, 2(1), 39 - 48.

7. TTS Sub-District Health Office. Health Profile of South Central Timor Sub-District. (2018). So'E: TTS Sub-District Health Office.

8. NTT Provincial Health Office. (2018). East Nusa Tenggara Provincial Health Profile 2018. Kupang: NTT Provincial Health Office

9. Banamtuan, M. F. (2016). Upaya Pelestarian Natoni (Tuturanadat) Dalam Budaya Timor Dawan (Atoni Meto). Paradigma, 6(1).

10. Hurlock, E.B. (2012). Developmental Psychology of a Lifespan Approach. Jakarta: Erlangga

11. Humune, H. (2017). Faktor-faktor yang mempengaruhi kunjungan kehamilan (k1) berdasarkan umur, pendidikan dan sosial budaya. Midwifery Journal of Akbid Griya Husada Surabaya, 4(2), 66-66.

12. Padila. (2014). Textbook of Nursing Maternity. Jogyakarta: Nuha Medika

13. Sumarni, S., Hidayat, S., \& Mulyadi, E. (2014). Hubungan gravida ibu dengan kejadian preeklampsia. WIRARAJA MEDIKA, 4(1).

14. Dever, A. (1984). Epidemiology in Health Services Management. Aspen Publication, Rockville

15. Banda. (2012). Factors Associated with Late Antenatal Care Attendane in Selected Rural and Urban Communities of the Copperbelt Province of Zambia

16. Green, L. (1980). Health Education: A Diagnosis Approach. The John Hopkins University: Myfield Publishing Company.

Cite This Article: Yudistira Kikhau (2021). Factors Affecting the Coverage of Ideal K1 Antenatal Services in the Work Area of the Batu Putih Public health center, Sub-District Batu Putih, District Timor Tengah Selatan. EAS J Nurs Midwifery, 3(2), 76-81. 